\title{
A Targeted Point Mutation in Thrombomodulin Generates Viable Mice with a Prethrombotic State
}

\author{
Hartmut Weiler-Guettler, ${ }^{\star \ddagger}$ Patricia D. Christie, ${ }^{\star}$ David L. Beeler, ${ }^{\star}$ Aileen M. Healy, ${ }^{\S}$ Wayne W. Hancock, Helen Rayburn, ${ }^{\star}$ \\ Jay M. Edelberg, ${ }^{*}$ and Robert D. Rosenberg* \\ *Department of Biology, Massachusetts Institute of Technology, Cambridge, Massachusetts 02139; ${ }^{\ddagger}$ Blood Research Institute, The Blood \\ Center of Southeastern Wisconsin, Milwaukee, Wisconsin 53226; ${ }^{\S}$ The Pulmonary Center, Boston University School of Medicine, Boston, \\ Massachusetts 02118; and ${ }^{\|}$The Sandoz Center, Beth Israel-Deaconess Medical Center, Boston, Massachusetts 02115
}

\begin{abstract}
The activity of the coagulation system is regulated, in part, by the interaction of thrombin with the endothelial cell receptor thrombomodulin with subsequent generation of activated protein $C$ and suppression of thrombin production. Our previous investigation demonstrated that ablation of the thrombomodulin gene in mice causes embryonic lethality before the assembly of a functional cardiovascular system, indicating a critical role for the receptor in early development. In the current study, we show that a single amino acid substitution in thrombomodulin dissociates the developmental function of the receptor from its role as a regulator of blood coagulation. Homozygous mutant mice with severely reduced capacity to generate activated protein $\mathrm{C}$ or inhibit thrombin develop to term, and possess normal reproductive performance. The above animals exhibit increased fibrin deposition in selected organs, which implies tissue specific regulation of the coagulation system that is supported by further evidence from the examination of mice with defects in fibrinolysis. The thrombomodulin-deficient animals provide a murine model to examine known or identify unknown genetic and environmental factors that lead to the development of thrombosis. (J. Clin. Invest. 1998. 101: 1983-1991.) Key words: thrombosis • protein C • animal model $\bullet$ development $\bullet$ gene targeting
\end{abstract}

\section{Introduction}

The coagulation system consists of a series of linked zymogenserine protease transformations that involve activated cofactors and appropriate cell surfaces that eventually lead to the generation of thrombin. The latter enzyme proteolytically converts fibrinogen to fibrin and also activates platelets to pro-

A portion of this work appeared in abstract form (1997. FASEB (Fed. Am. Soc. Exp. Biol.) J. 11:1452a) and was presented at the 17th International Congress of Biochemistry and Molecular Biology in San Francisco, CA on 28 August 1997.

Address correspondence to Dr. Hartmut Weiler-Guettler, Blood Research Institute, The Blood Center of Southeastern Wisconsin, 8727 Watertown Plank Road, Milwaukee, WI 53226. Phone: 414-9373813; FAX: 414-937-6284; E-mail: weiler@brisun.bcsew.edu

Received for publication 15 October 1997 and accepted in revised form 30 December 1997.

J. Clin. Invest.

(C) The American Society for Clinical Investigation, Inc. 0021-9738/98/05/1983/09 \$2.00

Volume 101, Number 9, May 1998, 1983-1991

http://www.jci.org duce a fibrin platelet plug. The action of the coagulation system is restrained by the continuous removal of fibrin via the fibrinolytic system and by natural anticoagulant mechanisms that suppress the generation of thrombin as well as the activation of platelets. For example, the binding of thrombin to the endothelial cell receptor thrombomodulin $(\mathrm{TM})^{1}$ induces a change in the enzyme which facilitates conversion by limited proteolysis of circulating protein $\mathrm{C}(\mathrm{PC})$ to activated protein $\mathrm{C}$ (APC) (1). Together with the cofactor protein S, APC proteolytically destroys activated coagulation cofactors $\mathrm{V}$ and VIII which are required for the production of thrombin. The binding of thrombin to TM also inhibits cleavage of fibrinogen and activation of platelets $(2,3)$. Thus, the protein C-TM pathway acts as a natural anticoagulant mechanism by suppressing excessive action of the coagulation system and also by directly inhibiting thrombin (4). The reduced function of this natural anticoagulant mechanism in humans leads to an increased susceptibility to thrombosis. Genetic deficiencies of PC and protein $\mathrm{S}$ are commonly inherited risk factors for thrombotic disease. A point mutation in the factor $\mathrm{V}$ gene rendering the activated cofactor somewhat resistant to APC cleavage (factor $\mathrm{V}$ Leiden) is the most frequent abnormality resulting in a predisposition to venous thrombosis $(4,5)$. It has been postulated, but not yet proven, that a malfunction of TM in humans represents a thrombotic risk (6-9).

We attempted previously to generate a murine model of thrombotic disease by using homologous recombination to delete the intronless TM gene (10). However, the complete loss of receptor function leads to embryonic lethality at about embryonic day 8.5 (E8.5), before the assembly of a functional cardiovascular system. Examination of TM-null embryos suggested that the developmental arrest was due to abnormal fetal maternal interactions and coincided with receptor expression on wild-type embryonic trophoblasts as well as parietal endoderm positioned to interact with maternally derived PC and thrombin $(10,11)$. In the current investigation, we provide biochemical and genetic evidence that the embryonic lethality of TM-null embryos is not caused by placental thrombosis secondary to the absence of APC generation and thrombin inhibition. Based upon these results, we used targeted mutagenesis of the TM gene to preserve the developmental role of the receptor while eliminating its effect on the coagulation system and generated a viable mouse strain with minimal capacity for TM-dependent APC production or thrombin inhibition. These TM-deficient animals were used to investigate the conse-

1. Abbreviations used in this paper: APC, activated protein $\mathrm{C}$; E, embryonic day; ES, embryonic stem; Glu, glutamic acid; pA, polyadenylation signal; PC, circulating protein C; Pro, proline; TM, thrombomodulin; tPA, tissue type plasminogen activator; uPA, urokinase type plasminogen activator. 
quences of this genetic abnormality that revealed a surprising organ-specific deposition of fibrin, which implies vascular beddependent regulation of the coagulation system. These data are supported by similar findings in mice with defects in fibrinolysis. The TM-deficient animals provide an in vivo test system to examine known or to identify unknown genetic and environmental factors that increase the risk of arterial or venous thrombosis.

\section{Methods}

Targeted mutagenesis of the murine TM locus and generation of mutant mice. A replacement-type gene targeting vector was constructed to substitute the glutamic acid (Glu) residue 404 (numbering starting at methionine 1 of mouse precursor protein) with proline (pro) (see Fig. 1). The native nucleotide sequence of a cloned genomic murine TM DNA fragment (10) was altered by means of inverse PCR on a circularized Pst \pm fragment (GenBank,) (positions 1105-1851; GenBank accession number X144320; primer 1 encoding the Glu-to-pro mutation, 5'-CATTGCAGAACATTGGGCACT-3', and primer 2 introducing a novel PvuII restriction site without altering the amino acid sequence, 5' -AAACTTCGTGCCCAGCTGACTG-3'). The altered sequence was incorporated into a 7.7-kb DNA fragment extending from an ApaI site $2.4 \mathrm{~kb} \mathrm{5'}$ relative to the transcription start to an SphI site located 900 bp downstream of the pA (polyadenylation signal) attachment site of the TM mRNA. A neomycin resistance gene (pgk neo $p A)$ was inserted at the same SphI site. An 800-bp SphI fragment served as the $3^{\prime}$ homology for recombination, followed by a counterselectable thymidine kinase gene $(\operatorname{pgkTKp} A) .2 \times 10^{8}$ embryonic stem (ES) cells (ESD3 cell line provided by R.O. Hynes, Massachusetts Institute of Technology, Cambridge, MA) were transfected by electroporation with the linearized targeting vector, and selected in medium containing G418 (Geneticin; GIBCO BRL, Grand Island, NY) and gancyclovir. ES cell clones having undergone homologous recombination were identified by Southern blot analysis (Fig. 1) and injected into C57Bl/6-blastocysts. Chimeric males were bred to $\mathrm{C} 57 \mathrm{~B} 1 / 6$ females to produce $\mathrm{F}_{1} \mathrm{TM}^{+/ \text {Pro }}$ mice. Animals with a hemizygous loss of function mutation due to the insertion of the bacterial $\beta$-galactosidase gene into the TM locus $\left(\mathrm{TM}^{+-}\right)$have been previously described (12). Mice deficient in urokinase type plasminogen activator (uPA) or tissue plasminogen activator (tPA) were obtained from Dr. Mulligan (13) (Whitehead Institute, Cambridge, MA).

Purification and characterization of TM. TM was purified from mouse lungs by two consecutive cycles of affinity chromatography on diisopropylfluorophosphate-thrombin (murine, 1,761 NIH U/mg) (Enzyme Research Laboratories, South Bend, IN) coupled to CNBractivated Separose 2B (Pharmacia Biotech, Piscataway, NJ) as previously described (14). Mouse lungs were dissected, flash-frozen in liquid nitrogen, and thoroughly homogenized in cold buffer containing $20 \mathrm{mM}$ TrisHCl, $\mathrm{pH} 7.5,0.25 \mathrm{M}$ sucrose, $50 \mathrm{U}$ heparin $/ \mathrm{ml}, 1 \mathrm{mM}$ benzamidine, 10 Kallikrein units aprotinin/ml, and $1 \mathrm{mM}$ PMSF. Insoluble material was sedimented, and extracted with the same buffer containing in addition $0.5 \%(\mathrm{vol} / \mathrm{vol})$ Triton $\mathrm{X}-100$. The extract was applied to the thrombin affinity column and $\mathrm{TM}$ was eluted with a $\mathrm{NaCl}$ gradient (0.1-1.2 M) in 0.02 M TrisHCl (pH 7.5) 0.1 mM EDTA, $1 \mathrm{mM}$ benzamidine, and $0.5 \%(\mathrm{vol} / \mathrm{vol}) \mathrm{Lubrol}$ PX. TM-containing fractions were identified with a TM-specific radioimmunoassay (15) and subjected to a second affinity chromatography. The purity and yield of TM were determined using silverstaining after urea/SDS-PAGE (16), semiquantitative amino acid analysis, total protein measurement, radioimmunoassay, and semiquantitative Western blot analysis with the same mAbs used in the radioimmunoassay. TM cofactor activity was determined by measuring the activation of protein $\mathrm{C}$ in the presence of varying concentrations of TM (wild-type: $0.17-7.5 \mathrm{nM}$; mutant: 0.3-12 $\mathrm{nM})$ and protein $\mathrm{C}(3.2-27 \mu \mathrm{M})$, and a fixed concentration of thrombin (wild-type: $0.5 \mathrm{nM}$; mutant: $5 \mathrm{nM}$ ). Affinity-purified murine TM and human thrombin (3,000 NIH-U/mg; Hematologic Technolo- gies, Essex Junction, VT) were incubated at $37^{\circ} \mathrm{C}$ with human protein $\mathrm{C}$ (benzamidine-free; Enzyme Research Laboratories) in assay buffer containing $0.02 \mathrm{M}$ Tris $\mathrm{HCl} \mathrm{pH} 7.4), 0.1 \mathrm{M} \mathrm{NaCl}, 2.5 \mathrm{mM} \mathrm{CaCl}$, $0.05 \% \mathrm{NaN}_{3}, 5 \mathrm{mg} / \mathrm{ml} \mathrm{BSA}$, and $0.05 \%$ (vol/vol) Triton X-100. Reactions were run for a fixed time period determined in pilot experiments to ensure linearity of the activation reaction and a maximum protein $\mathrm{C}$ consumption of $4 \%$. Protein $\mathrm{C}$ activation was quenched by the addition of excess hirudin and antithrombin III (Enzyme Research Laboratories). $10 \mu \mathrm{l}$ of the mixture was added to $55 \mu$ l of assay buffer containing the chromogenic substrate S 2366 (final concentration $0.8 \mathrm{mM}$ ), and the absorption at $405 \mathrm{~nm}$ was recorded continuously in a microplate reader. The amount of APC formed during the initial reaction was calculated from a standard curve generated with known amounts of human APC (Enzyme Research Laboratories). $K_{\mathrm{m}}$ and $V_{\max }$ were derived graphically from both Eadie-Hofstee and Lineweaver-Burk data representations. Apparent $K_{\mathrm{d}}$ values for binding of thrombin to TM were determined by extrapolation from the $x$ axis intercepts of double reciprocal plots of $1 /$ cofactor activity vs. $1 /\left[\right.$ thrombin]. $K_{\mathrm{d}}$ and $k_{\text {cat }}$ were further calculated with consistent results from the observed reaction velocities at different concentrations of TM, assuming reaction kinetics as described for essential enzymatic activation (17). Endothelial cells from the heart of newborn mice were isolated, cultured, and characterized essentially as previously described (18). Approximately $3 \times 10^{4}$ cells grown to confluency in one well of 96 -cluster culture dishes were maintained at $37^{\circ} \mathrm{C}$ on a plate warmer, rinsed three times with PBS, and then incubated with $72 \mu \mathrm{l}$ of $0.02 \mathrm{M}$ TrisHCl (pH 7.4), $0.1 \mathrm{M} \mathrm{NaCl}, 2.5 \mathrm{mM} \mathrm{CaCl}_{2}$, and $5 \mathrm{mg} / \mathrm{ml} \mathrm{BSA}$ containing thrombin at $5 \mathrm{nmol} /$ liter and $\mathrm{PC}$ at 6.6 $\mu \mathrm{mol} / \mathrm{liter}$, and the amount of APC generated during the incubation with cells was determined with the chromogenic substrate S 2366 assay as described above.

Determination of in vivo protein $C$ activation. The tail vein of anesthetized mice was injected with $20 \mu \mathrm{g}$ of human protein $\mathrm{C}$ in $100 \mu \mathrm{l}$ PBS. Blood samples were drawn 10 min later by heart puncture and the APC levels generated in vivo were determined with an immunocapture assay using the mAb 7D7B10 (generously supplied by C. Orthner, American Red Cross, Rockville, MD) and the chromogenic substrate S 2366 exactly as previously described (19). Standard curves were derived by adding known amounts of human APC to pooled plasma from wild-type mice.

Embryo transfer. $3 \mathrm{wk}$ old $\mathrm{TM}^{+/-}$females were treated with pregnant mare serum, stimulated $48 \mathrm{~h}$ later with human choriogonadotropin, and mated on that same day with $\mathrm{TM}^{+/-}$males. Blastocysts were collected on the third day and transferred into the uterus of pseudopregnant C57Bl/6 females. Embryos recovered $7 \mathrm{~d}$ later generally displayed 17-24 somites, had completed or almost completed the process of turning, and corresponded to late Theiler stage 14 to early stage 15 (20). The morphology of the embryos was recorded and subsequently DNA was isolated for genotyping by Southern blot analysis.

Detection of tissue fibrin. Experimental animals were anesthetized by intraperitoneal injection of $0.2 \mathrm{ml}$ avertin per $10 \mathrm{~g}$ of body weight and anticoagulated by intravenous injection of $400 \mathrm{U}$ heparin. After 3-5 min, animals were exsanguinated by cardiac puncture, tissues were dissected, rinsed briefly in PBS, frozen in liquid nitrogen, and the sample weight was recorded. The tissue was thoroughly homogenized with a polytron in $10 \mathrm{mM}$ sodium phosphate buffer, $(\mathrm{pH} 7.5)$ $0.1 \mathrm{M} \epsilon$-aminocaproic acid, $5 \mathrm{mM}$ trisodium EDTA, $10 \mathrm{U}$ aprotinin/ $\mathrm{ml}, 10 \mathrm{U}$ heparin/ml, and $2 \mathrm{mM}$ PMSF. The homogenate was agitated for $14 \mathrm{~h}$ at $4^{\circ} \mathrm{C}$, particulate material sedimented by centrifugation at $10,000 \mathrm{~g}$ for $10 \mathrm{~min}$, resuspended in extraction buffer without PMSF, sedimented again, and finally dispersed in $3 \mathrm{M}$ urea. The suspension was agitated for $2 \mathrm{~h}$ at $37^{\circ} \mathrm{C}$, vigorously vortexed, and centrifuged at $14,000 \mathrm{~g}$ for $15 \mathrm{~min}$. The supernatant was aspirated, and the sediment was dissolved at $65^{\circ} \mathrm{C}$ in reducing SDS sample buffer $(60 \mathrm{mM}$ TrisHCl (pH 6.8), 10\% glycerol, $2 \%$ SDS, and $0.1 \mathrm{M} \beta$-mercaptoethanol), subjected to SDS-PAGE (7.5\%; $5 \%$ stacking gel), and transferred to a PVDF membrane (Immobilon-P; Millipore Corp., Bedford, MA) by 
electroblotting. Fibrin $\beta$ chains were detected with the mouse antihuman fibrin mAb 59D8 (kindly provided by Dr. Marshall Runge, Galveston, Texas) and a chemiluminescence system (ECL; Amersham Corp., Arlington Heights, IL). Fibrin standards were prepared by clotting a known amount of murine fibrinogen (Sigma Chemical Co., St. Louis, MO) with an excess of thrombin in the absence of calcium. Dilution series of this fibrin preparation was included on gels next to experimental samples to estimate the amount of fibrin detected in tissue samples. At least five different exposures (between $5 \mathrm{~s}$ and $10 \mathrm{~min}$ ) were obtained from each membrane and analyzed with the NIH-image software. For quantitation, exposure times were chosen where the experimental sample's signal intensity fell into the linear range of the fibrin standard. Assay-to-assay variability was $<12 \%$. No significant loss of fibrin occurred during the enrichment procedure (absence of specific fibrin Western blot signals in supernatants at various steps). The specificity of anti-human fibrin antibody 59D8 for mouse $\beta$ fibrin was documented by analytic two-dimensional electrophoresis in conjunction with Western blotting. To this end, murine fibrin and murine fibrinogen were each separated by isoelectric focusing on an immobilized nonlinear $\mathrm{pH}$ gradient $(\mathrm{pH} 5-8$, Immobiline; BioRad Laboratories, Hercules, CA) and subsequently by SDS-PAGE (7.5\%; $5 \%$ stacking gel). The separated fibrinogen/fibrin chains were transferred to a PVDF membrane and then visualized with a rabbit anti-human fibrin(ogen) antiserum (DAKO Corp., Carpinteria, CA) and the anti-human fibrin antibody 59D8 using a chemiluminescent substrate for horseradish peroxidase as outlined above. The electrophoretic patterns revealed the specific staining of mouse $\beta$ fibrin, but not mouse fibrinogen, with the mAb 59D8 (see Fig. $4 A$ ).

Hypoxia-induced pulmonary thrombosis. Mice were exposed to normobaric hypoxia in a customized environmental chamber equipped with circulating fans, ammonia and carbon dioxide elimination systems, and an on-line oxygen sensor. Nitrogen was added gradually over a 30-40-min period until the oxygen concentration in the chamber was reduced to $8 \%$, and then maintained at this level. The mice were allowed free access to water and food during the above experimental manipulation. Animals were removed from the chamber after $16 \mathrm{~h}$ and either monitored for recovery, or immediately processed for the analysis of tissue fibrin deposition.

Immunohistology. For detection of cross-linked fibrin in tissues of mice, the animals were anticoagulated by intravenous injection of heparin. Tissue samples were dissected and then snap-frozen in cryomatrix (Tissue-Tek O.C.T. Cryomatrix; Sakura Finetek, Torrence, CA). Lungs were infiltrated with warm cryomatrix through the trachea before freezing. Frozen sections were fixed in $2 \%$ acetic acid ( $\mathrm{vol} / \mathrm{vol}) / 10 \%$ buffered formalin to wash out noncross-linked fibrinogen/fibrin (22). For localization of TM and fibrin in embryos, deciduas were isolated from the uteri of pregnant mice, fixed in buffered formalin, embedded in paraffin, sectioned, dewaxed, rehydrated, and finally postfixed for $1 \mathrm{~min}$ in cold acetone. Serial sections were incubated either with the anti-mouse TM antibody 201B (23) to identify TM-null embryos, or a rabbit anti-human fibrin(ogen) antibody (Dako Corp). Specific binding was detected with biotinylated secondary antibody-horseradish peroxidase complexes using a commercial assay system (Vectastain ABC; Vector Laboratories, Burlingame, CA).

\section{Results}

Embryonic lethality of TM-deficient embryos does not correlate with placental fibrin deposition. Previous attempts to generate TM knockout mice demonstrated that receptor-null embryos die at about E8.5 because of abnormal maternal-fetal interactions. Three types of investigations were conducted to determine whether increased coagulation system activity might be responsible for embryonic lethality. First, 56 fetoplacental units (embryo and surrounding decidual tissue) from intercrosses of $\mathrm{TM}^{+/-}$mice were isolated at E8.5 and inspected for the presence of increased amounts of fibrin. Immunohistologic studies demonstrated that 9 of 44 embryos exhibited a TM-null phenotype as shown by the complete absence of trophoblast reactivity with receptor-specific antibodies. Immunohistologic examination of these embryos for cross-linked fibrin failed to reveal any obvious increase in fibrin deposition associated with the TM-null phenotype. Indeed, fibrin deposition was generally more pronounced in decidual blood vessels of the mother than on the surface of the trophoblast, independent of embryonic genotype. Second, a selective restoration of TM expression on the maternal aspect of the decidua was undertaken to ascertain whether this manipulation was beneficial to the survival of TM-null embryos. Blastocysts were isolated from uteri of $\mathrm{TM}^{+/-}$females mated with $\mathrm{TM}^{+/-}$males, and then implanted into the uteri of wild-type females. Of 54 embryos transferred, 37 embryos were recovered at the equivalent of E9.5, of which 24 were $\mathrm{TM}^{+/-}, 13$ were wild type, and none were TM null. Third, tPA is coexpressed with TM on trophoblast, parietal endoderm, and maternal endothelial cells, whereas uPA is coexpressed with TM in trophoblast giant cells and maternal endothelial cells (24-26). Assuming that the levels of TM are not present in excess, the elimination of tPA/ uPA at these sites should lead to decreased survival of embryos with a partially disabled TM system. To this end, $\mathrm{TM}^{+/-}$ mice were crossed with tPA-null mice (13) to obtain $\mathrm{TM}^{+/-}$ $\mathrm{tPA}^{-1-}$ mice that were then interbred with $\mathrm{TM}^{+/+} \mathrm{tPA}^{-1-}$ mice. The progeny at 4-6 wk were monitored for a distortion in the transmission frequency of the mutated TM allele, as compared to the wild-type TM allele, in a fibrinolysis-deficient environment. The results demonstrated that the inactivated TM allele was transmitted normally $\left(83 \mathrm{TM}^{+/-} \mathrm{tPA}^{-1-}, n=175\right)$, and comparable results were obtained with uPA-null mice. The embryonic lethal phenotype of TM-null embryos persisted in a uPA- or tPA-deficient background (data not shown). The above studies reveal that $(a)$ the imminent developmental failure of TM-null embryos is not accompanied by increased placental fibrin deposition, $(b)$ the selective restoration of normal TM levels in the maternal circulation is insufficient to salvage TM-null embryos from resorption, and (c) the viability of heterozygous TM-deficient embryos is not reduced in a fibrinolysis-deficient environment.

Targeted mutagenesis of TM. Given the above observations, we investigated whether appropriate TM point mutations might eliminate the generation of APC and inhibition of thrombin while preserving regions of the receptor required for embryonic viability. The substitution of Glu 387 with Pro in the interdomain loop between EGF modules four and five of TM abolishes the ability of soluble recombinant human receptor to carry out in vitro thrombin-dependent APC generation (27). A gene replacement strategy was used to introduce the identical mutation into the coding region of the murine TM gene. The recombinant $\mathrm{TM}^{\mathrm{Pro}}$ allele was marked by a diagnostic PvuII site in close proximity to the primary mutation and by the presence of a selectable neomycin resistance gene expression cassette (Fig. 1). Male germline chimeras were obtained by blastocyst injection of correctly targeted ES cells and bred to $\mathrm{C} 57 \mathrm{Bl} / 6$ females to establish a line of $\mathrm{TM}^{+/ \text {Pro }}$ mice. Interbreeding of heterozygous $[\mathrm{F} 1 \times \mathrm{C} 57 \mathrm{Bl}] \mathrm{TM}^{+/ \text {Pro }}$ mice yielded homozygous $\mathrm{TM}^{\text {Pro/Pro }}$ offspring at a normal Mendelian frequency $\left(n=91 ; 21\right.$ wild-type, $42 \mathrm{TM}^{+/ \text {Pro }}$, and $\left.28 \mathrm{TM}^{\text {Pro/Pro }}\right)$. The cell type- and organ-specific distribution of $\mathrm{TM}^{\text {Pro }}$ was identical to the wild-type receptor, as judged by immunohis- 


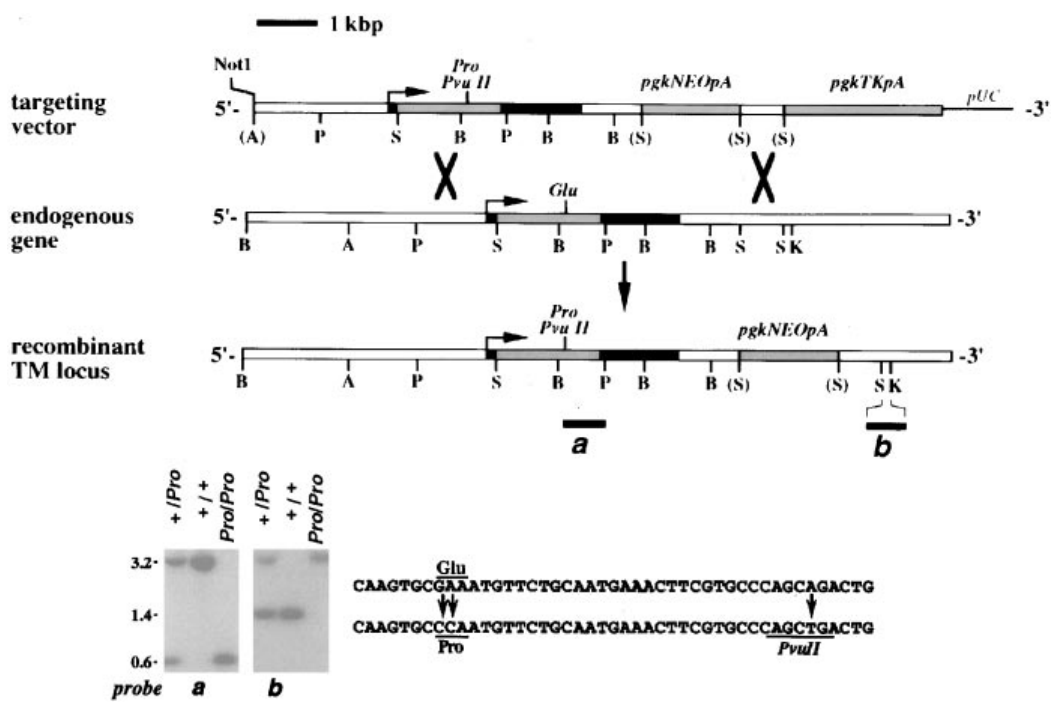

Figure 1. Targeted mutagenesis of the TM locus. The gene targeting vector shown on top was constructed to mutate the codon GAA (Glu) of the TM locus to CCA (Pro), and to introduce an adjacent point mutation (A to T) generating a diagnostic PvuII restriction site linked to the primary mutation without altering the amino acid sequence. The $5^{\prime}$ - and $3^{\prime}$-untranslated mRNA regions of the TM gene are shown in black; arrows show the transcriptional start site. Shaded boxes denote the neomycin resistance gene ( $p k g N E O p A)$ and the thymidine kinase gene $(\operatorname{pgkTKp} A)$. The indicated DNA fragments $a$ and $b$ (solid black bars, bottom) were used to identify ES cell clones having undergone homologous recombination and carrying the Glu-to-Pro mutation by Southern blot hybridization analysis of PvuII- (probe $a$, inset) or KpnI/BamHI-digested genomic DNA (probe $b$, inset). The nucleotide sequences of the wildtype (top) and targeted TM gene (bottom) are shown on the lower right.

tochemical analysis of tissue sections with antimurine TM-specific antibodies (data not shown). In addition, $\mathrm{TM}^{\text {Pro/Pro }}$ mice were bred to the $\mathrm{TM}^{+/-}$strain, in which one $\mathrm{TM}$ allele had been disrupted by insertion of the bacterial $\beta$-galactosidase gene (12). This cross yielded $\mathrm{TM}^{-/ \text {Pro }}$ mice carrying one inactivated and one $\mathrm{TM}^{\text {Pro }}$ allele. $\mathrm{TM}^{-/ \text {Pro }}$ mice of both sexes were fertile and transmitted the mutated TM alleles at the expected Mendelian frequencies $\left(\mathrm{TM}^{\text {Pro/Pro }} \times \mathrm{TM}^{-/ \text {Pro }}: 64 \mathrm{TM}^{-/ \text {Pro }} ; 59\right.$ $\left.\mathrm{TM}^{\text {Pro/Pro }} ; n=123\right)$. The offspring showed a balanced sex ratio (54\% male) and litter sizes $(8.1 \pm 1.8 ; n=15)$ were comparable to $\left(\mathrm{TM}^{+1-} \times \mathrm{C} 57 \mathrm{Bl} / 6\right)$ breeding pairs maintained in the same colony $(8.2 \pm 1.5 ; n=36)$. A cohort of 36 mutant mice $\left(19 \mathrm{TM}^{-/ \text {Pro }}\right.$ and $\left.17 \mathrm{TM}^{\text {Pro/Pro }}\right)$ maintained in the specific patho- gen-controlled facility at the Massachusetts Institute of Technology remained free of overt pathological manifestations for more than one year.

Mutant mice are deficient in the activation of protein $C$. The purification of TM from $\mathrm{TM}^{\mathrm{Pro} / \mathrm{Pro}}$ mice and wild-type mice was carried out by affinity chromatography of lung extracts on a DIP-thrombin matrix. Both preparations yielded receptor protein of comparable purity and identical molecular size as determined by denaturing gel electrophoresis (Fig. 2, top left). The relative yields during the purification steps were identical for both mutant and wild-type TM, as monitored with a receptor-specific radioimmunoassay (wild type, 38\%; $\mathrm{TM}^{\mathrm{Pro}}, 36 \%$ ). The absolute amounts of mutant TM, as compared to wild-
A

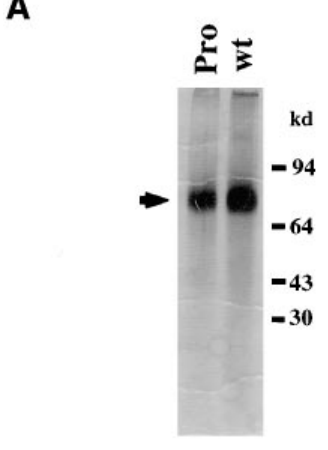

B

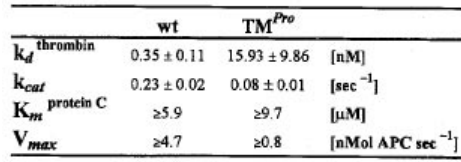

C

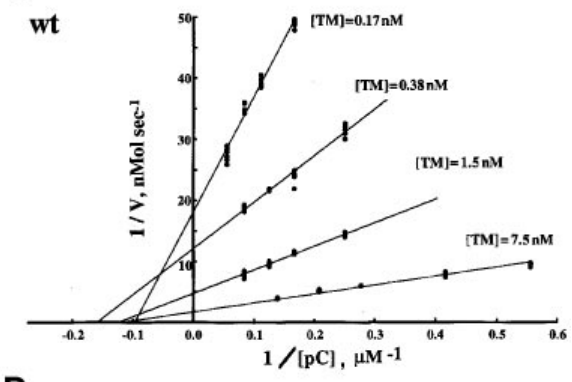

D

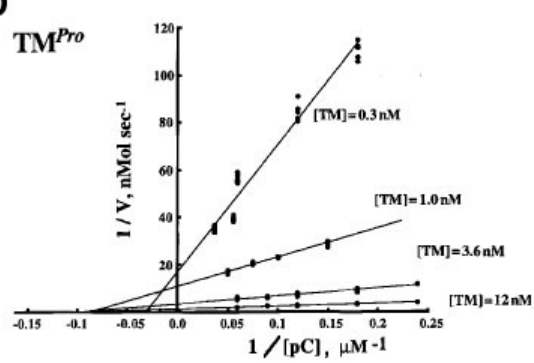

Figure 2. Kinetic analysis of TM cofactor activity. (A) TM purified from the lung of wild-type $(w t)$ mice and the lung of $\mathrm{TM}^{\text {Pro/Pro }}$ mice $\left(T M^{\text {Pro }}\right)$ by thrombin affinity chromatography was analyzed by electrophoresis under reducing conditions on urea containing SDS polyacrylamide gels (5\%), followed by silver staining. Mutant and wild-type receptor were comparable with respect to purity and apparent molecular weight $(\sim 78 \mathrm{kD})$. $(B)$ The kinetic reaction constants for the thrombin-dependent activation of protein $\mathrm{C}$ by TM are summarized. $k_{\text {cat }}$ and $k_{\mathrm{d}}^{\text {thrombin }}$ were calculated from the $V_{\max }$ apparent as a function of TM concentration (see methods). $k_{\mathrm{d}}$ thrombin was additionally derived by extrapolation from the $x$ axis intercepts of double reciprocal plots of $1 /$ velocity $(1 / V)$ vs. $1 /$ [thrombin]. The reaction constant $K_{\mathrm{m}}{ }^{\text {protein C }}$ was derived from the $y$ and $x$ axis intercepts of Lineweaver-Burk and EadieHofstee data representations. Values are given as the mean \pm SD. Differences between reaction constants of wild-type and mutant TM are significant at the $P<$ 0.005 confidence level (Student's $t$ test). Purified wildtype $(w t)(C)$ and mutant TM $\left(T M^{\text {Pro }}\right)(D)$ were incubated with human thrombin and human protein $C$. The amount of activated protein $\mathrm{C}$ formed over the course of the reaction was then determined with a second assay using a chromogenic substrate for activated protein C. Each data point in the $1 / \mathrm{V}$ vs. $1 /[\mathrm{pC}]$ plots shown represents the reaction velocity of APC formation in the initial activation reaction at a given concentration of protein $\mathrm{C}$ and $\mathrm{TM}$ with a minimum of four independent determinations. 
type receptor, recovered from lung extracts was decreased by approximately threefold ( $7.8 \mathrm{vs} .23 \mu \mathrm{g} / \mathrm{g}$ membrane fraction). The quantitative measurements of immunoreactive mutant and wild-type TM in total cellular protein lung extracts revealed a similar 2.4-fold reduction (radioimmunoassay with ${ }^{125}$ I-labeled $\mathrm{mAb} 201 \mathrm{~B} ; 591 \pm 51$ vs. $1,220 \pm 91 \mathrm{cpm} / \mu \mathrm{g}$ protein).

The purified $\mathrm{TM}^{\text {Pro }}$ and wild-type receptor preparations were subjected to a detailed kinetic analyses in the thrombindependent activation of protein C (Fig. 2). The mutant TM, as compared to wild-type receptor, exhibited a 1.6-fold augmentation in the $K_{\mathrm{m}}$ for PC, a 45-fold elevation in the $K_{\mathrm{d}}$ for thrombin, and a 2.7-fold reduction in the $k_{\text {cat }}$ for thrombindependent activation of PC (Fig. 2, bottom left). Direct measurements of cell surface TM cofactor activity were also carried out on primary cultures of neonatal cardiac microvascular endothelial cells isolated from mutant and wild-type mice. The activation of PC by mutant cells, as compared to wild-type cells, was decreased by 38 -fold $\left(0.29 \pm 0.07\right.$ vs. $11.2 \pm 3.4 \mathrm{~m}_{\mathrm{A} 405}$ $\mathrm{U} / \mathrm{min}$; thrombin $=5 \mathrm{nM}, \mathrm{PC}=6.6 \mu \mathrm{M})$. The latter estimate of $\mathrm{TM}^{\text {Pro }}$ function, as compared to wild-type receptor function, is in excellent accord with the expected value of $\sim 36$-fold, as calculated from the known amounts and kinetic constants of mutant receptor versus wild-type receptor in lungs. Based upon the above results, we estimate that at physiologically relevant levels of thrombin $(<1 \mathrm{nM})$, the $\mathrm{TM}^{\text {ProPro }}$ mice, as compared to wild-type mice, exhibit a decrease of $\sim 1,000$-fold with regard to $\mathrm{PC}$ activation and $\sim 100$-fold with respect to the binding of enzyme. Under the same condition, the $\mathrm{TM}^{-/ P r o}$ mice, as compared to wild-type mice, possess a reduction of 2,000 -fold with regard to PC activation and $\sim 200$-fold with respect to the binding of enzyme.

The extent of in vivo PC activation in $\mathrm{TM}^{-/ P r o}$ mice, as compared to wild type mice, was determined by intravenous injection of human PC with the subsequent estimation of APC generated under ambient conditions. The plasma concentrations of human PC were measured by specific immunoassay. The plasma levels of human APC were quantitated by trapping the enzyme with a species-specific antibody and then estimating the amount of bound enzyme by prolonged incubation with a chromogenic substrate. The latter approach for determining the generation of APC has been validated in humans by simultaneous measurements of the plasma concentrations of APC and PC activation peptide at differing plasma levels of PC (28). The infusion of $20 \mu \mathrm{g}$ of purified human $\mathrm{PC}$ into $\mathrm{TM}^{-/ \mathrm{Pro}}$ and wild-type mice resulted in steady state plasma concentrations of similar magnitude (Fig. 3 A). As observed in humans (28),

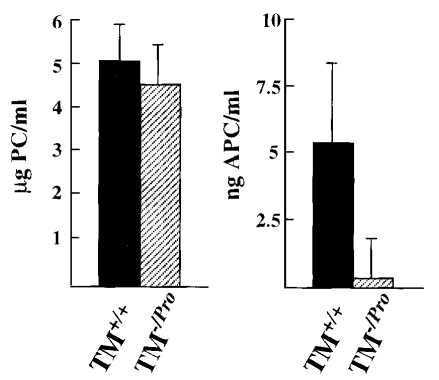

Figure 3. In vivo APC production in wild-type and mutant mice. Animals $(n=10$ for each group) were injected in the tail vein with $20 \mu \mathrm{g}$ of human protein $\mathrm{C}$ and subsequently the amounts of circulating protein $\mathrm{C}$ as well as APC were measured as described in Methods. Mutant mice $\left(T M^{-/ P r o}\right)$, as compared to wild-type mice $\left(T M^{+/+}\right)$exhibit undetectable amounts of circulating APC. wild-type mice converted $\sim 0.1 \%$ of PC into APC (Fig. $3 B$ ). In $\mathrm{TM}^{-/ \text {Pro }}$ mice, the circulating levels of human APC were below the limits of detection $(0.5 \mathrm{ng} / \mathrm{ml})$. The generation of APC in heterozygous $\mathrm{TM}^{+/-}$mice was indistinguishable from wildtype littermates (data not shown).

Fibrin deposition in mutant mice with defects in the TM or fibrinolytic mechanisms. The magnitude of fibrin deposition in mutant mice was estimated by quantitative Western blot analyses of urea-insoluble organ extracts using mAb 59D8 raised against the $\mathrm{NH}_{2}$ terminus of the human fibrin chain, which is exposed by thrombin-dependent cleavage of fibrinogen (21). The specificity of the 59D8 antibody for murine fibrin chain was documented by two-dimensional gel electrophoresis of murine fibrin or fibrinogen, transfer of separated proteins to a membrane, and detection of fibrin or fibrinogen with either the antifibrin antibody or antifibrin(ogen) antibody (Fig. 4A). The measurements of fibrin deposition in $\mathrm{TM}^{-/ \text {Pro }}$ mice, as compared to $\mathrm{TM}^{+/+}$mice, demonstrate a dramatic increase in fibrin deposition in spleen, heart, and lung (Fig. 4 B). Direct quantitation of the Western blots for $\mathrm{TM}^{+/-}$mice as compared to $\mathrm{TM}^{+/+}$mice shows a threefold elevation in heart and lung but not in other organs (Fig. $5 \mathrm{~A}$ ). Similar measurements carried out in $\mathrm{TM}^{-/ \text {Pro }}$ mice, as compared to $\mathrm{TM}^{+/+}$mice reveal 10- to 30-fold higher levels of fibrin in lung, heart, spleen, and liver whereas brain and kidney were indistinguishable (Fig. 5 $B)$. The distribution of fibrin in $\mathrm{TM}^{-/ P r o}$ mice, as compared to

A 59D8 anti-fibrin anti-fibrinogen

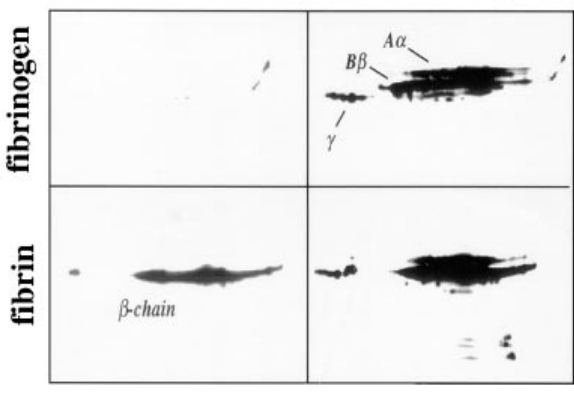

B

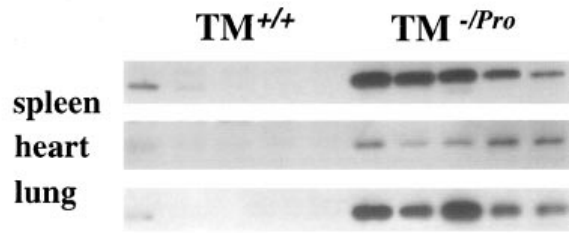

Figure 4. Western blot analysis of tissue fibrin deposition in mutant and wild-type mice. (A) Specificity of fibrin detection by Western blotting. Mouse fibrinogen and fibrin were resolved in two dimensions by isoelectric focusing followed by SDS-PAGE, transferred to a membrane support, and detected either with the fibrin-specific antibody 59D8, or with an antibody recognizing all fibrin/fibrinogen species. The 59D8 antibody detects specifically the thrombin-cleaved fibrin $\beta$ chain. (B) Western blot analysis of fibrin deposition. The amounts of $\beta$-fibrin chains per tissue mass were determined by densitometric analysis of $\mathrm{x}$-ray films. Each lane represents one wild-type $\mathrm{TM}^{+/+}$, or one mutant $\mathrm{TM}^{-/ \text {Pro }}$ mouse. 


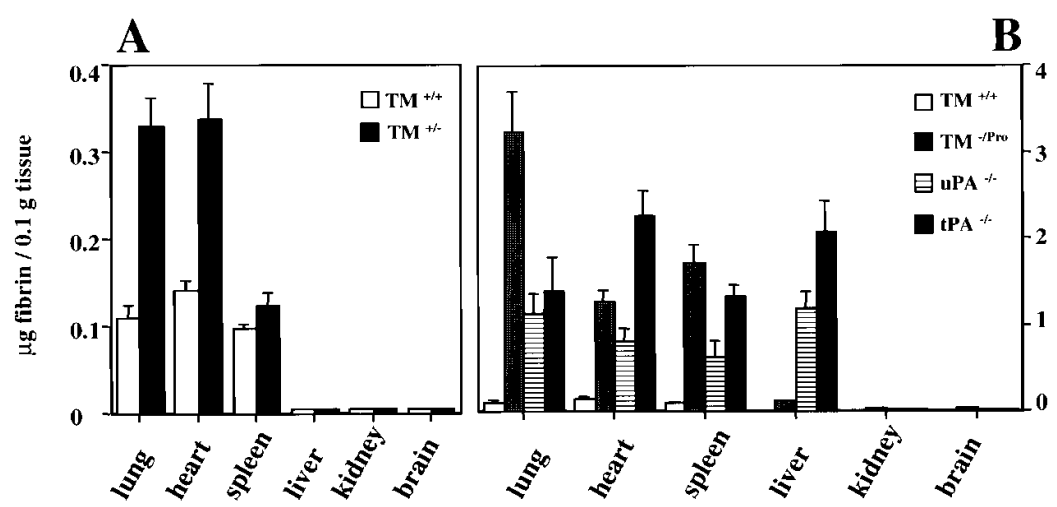

Figure 5. Quantitative comparison of fibrin deposition in mutant mice. $(A)$ Fibrin deposition in heterozygous TM-deficient $\left(\mathrm{TM}^{+-}\right)$mice as compared to wild-type $\left(T M^{+/+}\right)$mice. (B) Fibrin deposition in $T M^{-/ P r o}$ mice, as compared to wild-type mice $\left(T M^{+/+}\right)$, tPA-null $\left(t P A^{--}\right)$and uPA-null mice $\left(u P A^{-l-}\right)$ mice. The amount of fibrin present in the indicated organs of age (18-30 wk) and sex matched (male and female) wild-type and mutant mice was determined by quantitative Western blot analysis. Protein extracts were prepared as described in Methods. Fibrin chains were resolved by denaturing SDS-PAGE (7.5\%) and $\beta$ chains quantitated with the 59D8 antibody using a chemiluminescent substrate for horseradish peroxidase in comparison to standard curves generated with known amounts of purified mouse fibrin. Data was obtained from duplicate determinations on at least eight different animals. Values are expressed as the $\mu \mathrm{g}$ of $\beta$-fibrin per $0.1 \mathrm{~g}$ of wet tissue weight \pm standard error. Average differences in fibrin deposition of $\sim 50 \%$ are statistically significant at $P>0.05$ (Student's paired $t$ test).

$\mathrm{TM}^{+/+}$mice, was also established by immunohistochemical analyses using a technique specific for cross-linked fibrin (22). Small blood clots and intravascular fibrin were detected in the vascular bed of lung, spleen, and heart (Fig. 6; lung and spleen, heart not shown). The capillaries, arteries, and veins in the lungs of $\mathrm{TM}^{\text {Pro/Pro }}$ or $\mathrm{TM}^{-/ \text {Pro }}$ animals were marked as either positive or negative for the presence of fibrin. The extent of fibrin deposition within pulmonary vessels, assessed by the examination of 30 sequential fields per section of lung and using four sections per lung from three different animals revealed positive staining in $21 \pm 15 \%$ of capillaries, $58 \pm 15 \%$ of veins, and $62 \pm 11 \%$ of arteries which documents fibrin deposition at all levels of the vascular system. It should also be noted that despite a twofold difference in the levels of receptor, $\mathrm{TM}^{-/ \text {Pro }}$ mice, as compared to $\mathrm{TM}^{\text {Pro/Pro }}$ mice, possessed comparable amounts of fibrin deposition in the four organs $\left(\mathrm{TM}^{-/ \text {Pro }}\right.$ vs.

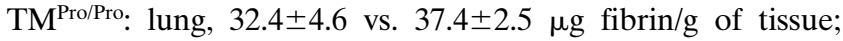
heart, $12.8 \pm 1.2$ vs. $9.7 \pm 1.2 \mu \mathrm{g}$ fibrin/g of tissue; spleen, $17.1 \pm$ 2.1 vs. $17.9 \pm 1.2 \mu \mathrm{g}$ fibrin/g of tissue; liver, $1.1 \pm 1.3$ vs. $1.8 \pm 0.3$ $\mu \mathrm{g}$ fibrin/g of tissue). These observations reinforce our conclusion that $\mathrm{TM}^{\text {Pro/Pro }}$ mice exhibit no significant PC cofactor activity since further reduction of receptor levels by a factor of two fails to increase the severity of fibrin deposition.

We also wished to ascertain whether mice with reduced or virtually absent functional levels of TM exhibited augmented fibrin deposition when subjected to a thrombogenic challenge. Previous studies with wild-type mice demonstrated that prolonged hypoxia increases expression of tissue factor in monocytes/macrophages and pulmonary blood vessel endothelial cells with resultant pulmonary thrombosis (29). Therefore, $\mathrm{TM}^{-/ \text {Pro }}$ mice, $\mathrm{TM}^{+/-}$mice, and $\mathrm{TM}^{+/+}$mice were maintained for $16 \mathrm{~h}$ under reduced oxygen tensions $\left(8 \% \mathrm{O}_{2}\right)$, monitored for survival and recovery, and then analyzed for fibrin deposition as described above. Total cellular TM levels in the lung, spleen, and heart were unchanged as determined by specific radioimmunoassay (wild type, $n=5$ ) (lung hypoxic vs. normoxic: $2,890 \pm 198$ vs. $2,437 \pm 212 \mathrm{cpm} / \mu \mathrm{g}$ protein; spleen: $156 \pm$ 14 vs. $139 \pm 16 \mathrm{cpm} / \mu \mathrm{g}$ protein; heart: $585 \pm 43 \mathrm{vs.} 693 \pm 81 \mathrm{cpm} /$ $\mu \mathrm{g}$ protein). Survival and postexperimental viability during a 2-wk observation period were identical for all three experimental groups ( $n=5$ /group). In wild-type mice, prolonged hypoxia lead to an additional four- to fivefold increase in fibrin deposition in lung, whereas in $\mathrm{TM}^{+/-}$mice or $\mathrm{TM}^{-/ \text {Pro }}$ mice the same manipulation produced an additional 10-fold increase in fibrin deposition in the same organ (wild-type mice, $1.1 \pm 0.1$ vs. $5.0 \pm 0.7 \mu \mathrm{g}$ fibrin $/ \mathrm{g}$ of tissue; $\mathrm{TM}^{+/-}, 3.3 \pm 0.3 \mathrm{vs} .31 .9 \pm 3.8 \mu \mathrm{g}$ fibrin/g of tissue; $\mathrm{TM}^{-/ \mathrm{Pro}}, 32.4 \pm 4.6$ vs. $270.3 \pm 46.9 \mu \mathrm{g}$ fibrin $/ \mathrm{g}$ of tissue).

The above results demonstrate that mice with a significant functional defect in the TM mechanism exhibit increased fibrin deposition of varying magnitude in the vascular beds of selected organs and that the same mice subjected to a thrombogenic challenge respond with an enhanced activation of the coagulation mechanism in the lungs. To determine whether similar patterns of organ-specific fibrin deposition also occur in mice with defects in the fibrinolytic mechanism, investigations like those outlined for TM-deficient mice, were carried out in tPA- or uPA-null mice. These two strains of mice have not been examined previously by quantitative techniques for fibrin deposition, although histologic techniques have documented scattered fibrin aggregates in the liver of uPA-null mice (13). The tPA- and uPA-null mice, as compared to wildtype mice, revealed 10- to 20 -fold increased levels of fibrin deposition in lung, spleen, heart, and liver, whereas the brain and kidney appeared again free of fibrin (Fig. 5 B). However, the overall pattern of fibrin deposition in $\mathrm{TM}^{-/ \text {Pro }}$ mice, uPAand tPA-null mice was distinctive. For example, $\mathrm{TM}^{-/ \text {Pro }}$ mice versus tPA-null mice, exhibit ratios of fibrin deposition in lung versus heart that differ by four- to fivefold (Fig. $5 \mathrm{~B}$ ). Furthermore, tPA- or uPA-null mice as compared to $\mathrm{TM}^{-/ P r o}$ mice, possess levels of fibrin deposition in liver that are increased by 10- to 20 -fold (Fig. 5 B).

\section{Discussion}

In the current investigation, we determined whether the early embryonic death of TM-null embryos is due to the lack of receptor expression on fetal trophoblasts, parietal endoderm, or uterine endothelial cells which may result in excessive placental fibrin deposition. Indeed, we note that the presence of large amounts of fibrin at the maternal-fetal interface could interfere with nutrient exchange, and hence lead to embryonic lethality during the subsequent period of accelerated growth and development. Several independent lines of evidence suggest that the developmental requirement for TM is unrelated to its regulation of coagulation system activity. The immunohisto- 


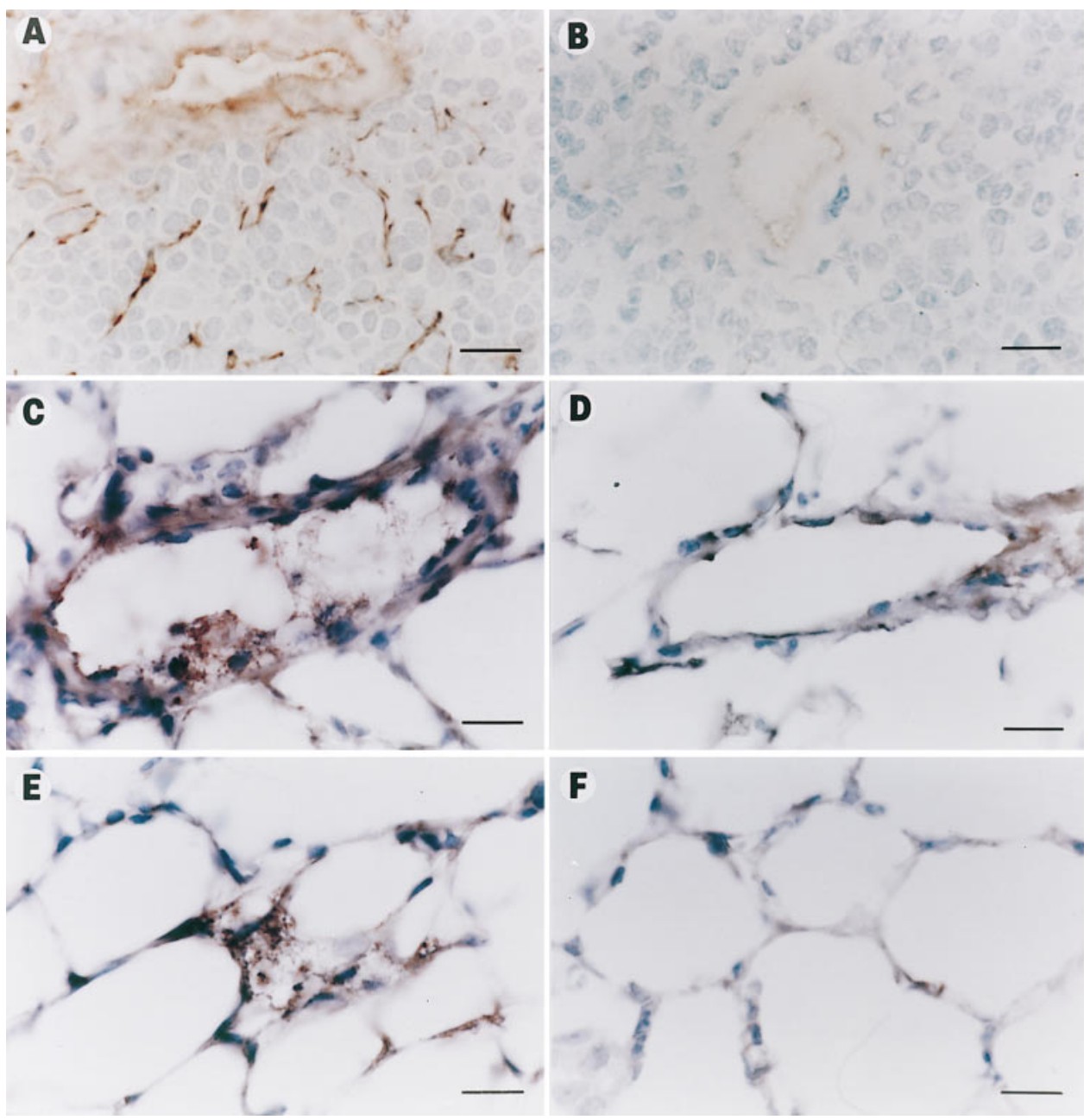

Figure 6. Immunohistological detection of fibrin. Frozen tissue sections of mutant $T M^{-/ P r o}(A, C$, and $E)$ and wild type-mice $(B, D$, and $F)$ were fixed in acidic formalin to wash out soluble fibrinogen/fibrin, reacted with the fibrinogen/fibrin-specific antibody, and counterstained with hematoxylin. The dark brown horseradish peroxidase reaction product shows fibrin present in the microvasculature and arterioles of $(A)$ spleen, $(C)$ pulmonary arterioles, and $(E)$ alveolar capillaries of $\mathrm{TM}^{-/ \text {Pro }}$ mice. No significant staining was observed in $(B)$ splenic or $(D$ and $F$ ) pulmonary vasculature of wild-type animals. Bar represents $10 \mu \mathrm{m}$. logical survey of fetoplacental units showed that imminent resorption of TM-null embryos at E8.5 is not preceded by a localized deposition of fibrin at the boundary between embryonic trophoblast and maternal decidual tissue. The selective restitution of maternal TM by transplantation of TM-null embryos into wild-type females failed to permit normal embryonic survival. The breeding of $\mathrm{TM}^{+/-} \mathrm{PAA}^{-1-}$ mice with $\mathrm{TM}^{+/+} \mathrm{PPA}^{-/-}$mice should significantly increase placental fibrin deposition in $\mathrm{TM}^{+/-}$embryos, as compared to receptor wild-type embryos, because TM and tPA are coexpressed in trophoblasts, or parietal endoderm or uterine endothelial cells (24-26). However, the extent of transmission of the mutated $\mathrm{TM}$ allele, as compared to the receptor wild-type allele, was identical, which implies that fibrin deposition is not responsible for embryonic lethality.

The relationship between TM-dependent anticoagulation and embryonic survival was directly assessed by replacing the wild-type receptor allele with a mutant receptor allele possessing essentially no capacity to generate APC or inhibit thrombin. In contrast to a complete loss of TM function, the selective elimination of the anticoagulant properties of the receptor was compatible with embryonic viability. The biochemical characterization of purified $\mathrm{TM}^{\text {Pro }}$ and the quantitation of cell surface levels of $\mathrm{TM}^{\mathrm{Pro}}$, as compared to wild-type receptor, predict that

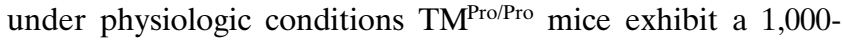

fold reduction in APC production as well as a 100-fold reduction in thrombin binding, whereas $\mathrm{TM}^{-/ \text {Pro }}$ mice possess a 2,000-fold reduction in APC production and a 200-fold reduction in thrombin binding. The actual rate of APC generation could vary on the endothelial cell surface because of differences between free and membrane-bound TM, sequestration of reaction components by phospholipids, or interaction of PC with the PC receptor (30). Therefore, we also measured thrombin-dependent conversion of PC to APC on mutant and wild-type cardiac endothelial cells which showed that the relative rates of APC generation are virtually identical to that predicted from studies of purified $\mathrm{TM}^{\text {Pro }}$ versus wild-type receptor isolated from lung extracts.

The survival of $\mathrm{TM}^{\text {Pro/Pro }}$ or $\mathrm{TM}^{-/ \text {Pro }}$ embryos in normal Mendelian ratios supports the hypothesis that the receptor must play a critical role other than coagulation system regulation at the maternal-fetal interface. Indeed, we have suggested previously that the binding of the $\mathrm{NH}_{2}$-terminal TM lectin-like domain to a placental component might induce cell signaling via the intracytoplasmic tail which is required for embryonic survival (10). In this regard, it is of interest to note that transfection of melanoma cells with TM lacking the $\mathrm{NH}_{2}$-terminal lectin domain or the cytoplasmic tail, as compared to wild-type receptor, fails to inhibit cell proliferation under in vitro conditions or after transplantation into mice (31). The existence of a 
separate developmental function for TM has interesting implications with regard to the evolutionary assembly of the complex blood coagulation mechanism. It is tempting to speculate that TM may have initially evolved to facilitate embryonic survival with subsequent recruitment of the receptor to serve as a regulator of the coagulation system that might have occurred via point mutations as shown in this study. Recent data from tissue factor (32-34) and factor V (35) mouse knockouts lend support to the notion that blood coagulation components have alternative developmental functions. The ablation of either gene leads to early fetal death with potential abnormalities in extraembryonic blood vessel function. Moreover, the developmental role of these gene products appears to be independent of fibrin formation since fibrinogen-deficient mice $(36,37)$ do not exhibit comparable abnormalities. The survival of $\mathrm{TM}^{\text {Pro/Pro }}$ as well as $\mathrm{TM}^{-/ \text {Pro }}$ mice and the availability of $\mathrm{TM}^{+/-}$mice allowed us to investigate the consequences of disrupting, to a varying extent, a natural anticoagulant mechanism. Using a plasma immunocapture assay for APC generation, we demonstrated that $\mathrm{TM}^{-/ \text {Pro }}$ mice exhibited no detectable APC generation whereas $\mathrm{TM}^{+/-}$mice showed no significant alteration in APC production under ambient conditions. Using a sensitive immunoblot assay for the fibrin $\beta$ chain, we determined the magnitude of fibrin deposition in tissues. The $\mathrm{TM}^{-/ P r o}$ mice or $\mathrm{TM}^{\text {Pro/Pro }}$ mice, as compared to wild-type mice, exhibited 10- to 30-fold greater amounts of fibrin deposition in lungs, heart, spleen, and liver, but not other organs. The intravascular localization of fibrin in arterioles, and capillaries as well as venules was documented by immunohistological techniques that conformed with the known expression pattern of the receptor. Similar studies were conducted with $\mathrm{TM}^{+/-}$mice, as compared to wild-type mice, which showed a threefold elevation in fibrin deposition in the same organs. Both $\mathrm{TM}^{-/ \text {Pro }}$ and $\mathrm{TM}^{+/-}$mice were then subjected to a thrombogenic challenge that increases tissue factor expression in the lung with essentially no effect on TM levels. The data revealed that mutant mice, as compared to wild-type mice, produce more extensive pulmonary fibrin deposition relative to the ambient state. Thus, significant reductions in TM levels lead to dysregulation of the coagulation system with augmented fibrin deposition under ambient conditions as well as after a thrombogenic challenge.

We infer from the above observations that the murine coagulation mechanism generates thrombin under normal conditions, and that the production as well as the action of the enzyme is opposed by the TM-PC pathway. However, dysfunction of the TM-PC mechanism fails to lead to complete fibrin occlusion of all vascular beds which shows that other inhibitory pathways counteract this defect. These additional natural anticoagulant mechanisms include: (a) tissue factor pathway inhibitor, or antithrombin-heparan sulfate proteoglycan pathways that inhibit the coagulation cascade, $(b)$ the nitric oxide synthetase, prostacyclin synthetase, and ectoADPase pathways that modulate platelet activation, or $(c)$ tPA and uPA that accelerate fibrinolytic system function. On the other hand, the combined activity of all the above mechanisms is not sufficient to entirely compensate for the TM-PC defect. Evidently the individual pathways are not redundant and have only a limited capacity to buffer hemostatic disturbances.

Surprisingly, the extent of fibrin deposition differs significantly from organ to organ which suggests that the coagulation system is regulated in a tissue-specific manner. This hypothesis is supported by the observation that $\mathrm{TM}^{-/ \text {Pro }}$ mice, in contrast to either tPA- or UPA-null mice, differ greatly in the extent of fibrin deposition in lung, heart, and liver. The minimal increase in fibrin deposition in the liver upon elimination of the TM mechanism is consistent with the low known expression levels of the receptor in this organ $(38,39)$. The lung, on the other hand, appears particularly sensitive to a loss of TM activity, although the receptor is expressed at comparably abundant levels in pulmonary endothelial cells as compared to other vascular beds (38). This susceptibility is also highlighted by the increased pulmonary fibrin deposition in heterozygous $\mathrm{TM}^{+/-}$ mice that exhibit normal systemic levels of circulating APC. Remarkably, all mutant mice fail to show increased fibrin deposition in brain or kidney implying that the coagulation system is regulated in a very different manner in these vascular beds. These organ-dependent variations in fibrin deposition are most probably secondary to local alterations in the levels of endothelial cell activators and inhibitors that regulate the coagulation cascade, platelet activation, or fibrinolysis which may help to explain the focal nature of thrombotic disease.

Investigations of humans demonstrate that the generation and inhibition of thrombin is precisely balanced under normal conditions, but that enzyme production slightly exceeds neutralization for a period of time before a thrombotic event, which has been termed the hypercoagulable state (40). It is presumed that the hypercoagulable state gradually leads to activation of cofactors and platelets that in turn generate a burst of thrombin that initiates overt thrombosis. The mutant mice described above represent the first animal model of the hypercoagulable state since increased generation of thrombin is readily apparent in the absence of overt thrombotic episodes that shorten life span. We also note that $\mathrm{TM}^{\text {Pro/Pro }}$ or $\mathrm{TM}^{-/ \text {Pro }}$ mice, as compared to $\mathrm{TM}^{+/-}$mice, differ in the amounts of fibrin deposited as a function of genotype and that the severity of this phenotype is worsened upon application of a thrombogenic challenge. These observations suggest that the TM defect is capable of interacting with other genetic and environmental factors to initiate thrombosis.

The penetrance of thrombosis is highly variable in humans afflicted with genetic abnormalities in the TM mechanism, such as PC or protein S deficiency or factor V Leiden. The incidence of this disease is dramatically augmented by the presence of other genetic defects or environmental factors (4, 41-43). It should be possible to use the mutant TM mice, in conjunction with quantitative measures of fibrin deposition, to investigate known or identify unknown genetic and environmental factors that enhance development of arterial or venous thrombosis. In part, these studies may be carried out by crossbreeding with knockout mice possessing genetic abnormalities in other physiologic systems. Thus, the multiple interactions between genetic and acquired abnormalities in the coagulation mechanism, lipid metabolism, the immune system, and blood pressure regulation which might lead to thrombotic disease could be examined in a strictly controlled and quantitative manner. The above investigations have the potential to greatly increase our understanding of the molecular basis of arterial and venous thrombosis in humans.

\section{Acknowledgments}

We would like to thank Drs. S. Kennel, M. Runge, and C. Orthner for providing copious amounts of antibodies 34A, 201B, 59D8, and 7D7B10; J. Liau, P. Su, and S. Parise for maintaining the mouse colo- 
nies; and Drs. C. Lawson and D. Stern for their support in initial hypoxia experiments.

This work was supported by National Institutes of Health grant PO1-41484.

\section{References}

1. Esmon, C.T., and W.G. Owen. 1981. Identification of an endothelial cell cofactor for thrombin-catalyzed activation of protein C. Proc. Natl. Acad. Sci. USA. 78:2249-2252.

2. Esmon, N.L., R.C. Carroll, and C.T. Esmon. 1983. Thrombomodulin blocks the ability of thrombin to activate platelets. J. Biol. Chem. 258:1223812242 .

3. Esmon, C.T., N.L. Esmon, and K.W. Harris. 1982. Complex formation between thrombin and thrombomodulin inhibits both thrombin-catalyzed fibrin formation and factor V activation. J. Biol. Chem. 257:7944-7947.

4. Dahlback, B. 1995. The protein C anticoagulant system: inherited defects as basis for venous thrombosis. Thromb. Res. 77:1-43.

5. Bertina, R.M., B.P. Koeleman, T. Koster, F.R. Rosendaal, R.J. Dirven, H. van de Ronde, and P.H. Reitsma. 1994. Mutation in blood coagulation factor $\mathrm{V}$ associated with resistance to activated protein C. Nature. 369:64-67.

6. Ohlin, A.K., and R.A. Marlar. 1995. The first mutation identified in the thrombomodulin gene in a 45-year-old man presenting with thromboembolic disease. Blood. 85:330-336.

7. van der Velden, P.A., T. Krommenhoek-Van Es, C.F. Allaart, R.M. Bertina, and P.H. Reitsma. 1991. A frequent thrombomodulin amino acid dimorphism is not associated with thrombophilia. Thromb. Haemost. 65:511-513.

8. Faioni, E.M., G. Merati, F. Peyvandi, P.M. Bettini, and P.M. Mannucci. 1997. The $\mathrm{G}(1456)$ to $T$ mutation in the thrombomodulin gene is not frequent in patients with venous thrombosis. Blood. 89:1467.

9. Norlund, L., J. Holm, B. Zoller, and A.K. Ohlin. 1997. A common thrombomodulin amino acid dimorphism is associated with myocardial infarction. Thromb. Haemost. 77:248-251.

10. Healy, A.M., H.B. Rayburn, R.D. Rosenberg, and H. Weiler. 1995. Absence of the blood-clotting regulator thrombomodulin causes embryonic lethality in mice before development of a functional cardiovascular system. Proc. Natl. Acad. Sci. USA. 92:850-854.

11. Weiler-Guettler, H., W.C. Aird, H. Rayburn, M. Husain, and R.D. Rosenberg. 1996. Developmentally regulated gene expression of thrombomodulin in postimplantation mouse embryos. Development. 122:2271-2281.

12. Weiler-Guettler, H., W.C. Aird, M. Husain, H. Rayburn, and R.D. Rosenberg. 1996. Targeting of transgene expression to the vascular endothelium of mice by homologous recombination at the thrombomodulin locus. Circ. Res. 78:180-187.

13. Carmeliet, P., L. Schoonjans, L. Kieckens, B. Ream, J. Degen, R. De Vos, J.J. van den Oord, D. Collen, and R.C. Mulligan. 1994. Physiological consequences of loss of plasminogen activator gene function in mice. Nature. 368: $419-424$

14. Esmon, N.L., W.G. Owen, and C.T. Esmon. 1982. Isolation of a membrane-bound cofactor for thrombin-catalyzed activation of protein C. J. Biol. Chem. 257:859-864.

15. Kennel, S.J., T. Lankford, B. Hughes, and J.A. Hotchkiss. 1988. Quantitation of a murine lung endothelial cell protein, P112, with a double monoclonal antibody assay. Lab. Invest. 59:692-701.

16. Swank, R.T., and K.D. Munkres. 1971. Molecular weight analysis of oligopeptides by electrophoresis in polyacrylamide gel with sodium dodecyl sulfate. Anal. Biochem. 39:462-477.

17. Dixon, M., and E.C. Webb. 1979. Enzymes. Academic Press, New York. 381-389.

18. Lodge, P.A., C.E. Haisch, and F.T. Thomas. 1992. A simple method of vascular endothelial cell isolation. Transplant. Proc. 24:2816-2817.

19. Orthner, C.L., B. Kolen, and W.N. Drohan. 1993. A sensitive and facile assay for the measurement of activated protein $\mathrm{C}$ activity levels in vivo. Thromb. Haemost. 69:441-447.

20. Kaufman, M.H. 1992. The Atlas of Mouse Development. Academic Press, San Diego, CA.

21. Hui, K.Y., E. Haber, and G.R. Matsueda. 1983. Monoclonal antibodies to a synthetic fibrin-like peptide bind to human fibrin but not fibrinogen. Science. 222:1129-1132.

22. Dvorak, H.F., D.M. Form, E.J. Manseau, and B.D. Smith. 1984. Pathogenesis of desmoplasia. J. Natl. Cancer Inst. 73:1195-1201.

23. Ford, V.A., J.E. Wilkinson, and S.J. Kennel. 1993. Thrombomodulin distribution during murine development. Roux's Arch. Dev. Biol. 202:364-370.

24. Strickland, S., and W.G. Richards. 1992. Invasion of the trophoblasts. Cell. 71:355-357.

25. Cross, J.C., Z. Werb, and S.J. Fisher. 1994. Implantation and the placenta: key pieces of the development puzzle. Science. 266:1508-1518.

26. Sappino, A.P., J. Huarte, D. Belin, and J.D. Vassalli. 1989. Plasminogen activators in tissue remodeling and invasion: $\mathrm{mRNA}$ localization in mouse ovaries and implanting embryos. J. Cell Biol. 109:2471-2479.

27. Clarke, J.H., D.R. Light, E. Blasko, J.F. Parkinson, M. Nagashima, K McLean, W.H. Andrews, J. Morser, and C.B. Glaser. 1993. The short loop between epidermal growth factor-like domains 4 and 5 is critical for human thrombomodulin function. J. Biol. Chem. 268:6309-6315.

28. Conard, J., K.A. Bauer, A Gruber, J.H. Griffin, H.P. Schwarz, M. Horellou, and R.D. Rosenberg. 1993. Normalization of markers of coagulation activation with a purified protein $\mathrm{C}$ concentrate in adults with homozygous protein C deficiency. Blood. 82:1159-1164.

29. Lawson, C.A., S.D. Yan, S.F. Yan, H. Liao, Y.S. Zhou, J. Sobel, W. Kisiel, D.M. Stern, and D.J. Pinsky. 1997. Monocytes and tissue factor promote thrombosis in a murine model of oxygen deprivation. J. Clin. Invest. 99:17291738 .

30. Stearns-Kurosawa, D.J., S. Kurosawa, J.S. Mollica, G.L. Ferrell, and C.T. Esmon. 1996. The endothelial cell protein C receptor augments protein C activation by the thrombin-thrombomodulin complex. Proc. Natl. Acad. Sci. USA. 93:10212-10216.

31. Zhang, Y., H. Weiler-Guettler, J. Chen, O. Wilhelm, Y. Deng, F. Qui, K. Nakagawa, M. Klevesath, S. Wilhelm, H. Bohrer, et al. 1998. Thrombomodulin modulates growth of tumor cells independent of its anticoagulant activity. J. Clin. Invest. 101:1301-1309.

32. Carmeliet, P., N. Mackman, L. Moons, T. Luther, P. Gressens, H. Demunck, M. Kasper, G. Breier, P. Evrard, M. Muller, et al. 1996. Role of tissue factor in embryonic blood vessel development. Nature. 383:73-75.

33. Toomey, J.R., K.E. Kratzer, N.M. Lasky, J.J. Stanton, and G.J. Broze, Jr. 1996. Targeted disruption of the murine tissue factor gene results in embryonic lethality. Blood. 88:1583-1587.

34. Bugge, T.H., Q. Xiao, K.W. Kombrinck, M.J. Flick, K. Holmback, M.J. Danton, D.P. Witte, K. Fujikawa, E.W. Davie, and J.L. Degen. 1996. Fatal embryonic bleeding events in mice lacking tissue factor, the cell-associated initiator of blood coagulation. Proc. Natl. Acad. Sci. USA. 93:6258-6263.

35. Cui, J., K.S. O'Shea, A. Purkayastha, T.L. Saunders, and D. Ginsburg 1996. Fatal haemorrhage and incomplete block to embryogenesis in mice lacking coagulation factor V. Nature. 384:66-68.

36. Suh, T.T., K. Holmback, N.J. Jensen, C.C. Daugherty, K. Small, D.I. Simon, S. Potter, and J.L. Degen. 1995. Resolution of spontaneous bleeding events but failure of pregnancy in fibrinogen-deficient mice. Genes Dev. 9: 2020-2033.

37. Bugge, T.H., K.W. Kombrinck, M.J. Flick, C.C. Daugherty, and M. Danton. 1996. Loss of fibrinogen rescues mice from the pleiotropic effects of plasminogen deficiency. Cell. 87:709-719.

38. Ford, V.A., C. Stringer, and S.J. Kennel. 1992. Thrombomodulin is preferentially expressed in Balb/c lung microvessels. J. Biol. Chem. 267:5446-5450.

39. Dittman, W.A., and P.W. Majerus. 1990. Structure and function of thrombomodulin: a natural anticoagulant. Blood. 75:329-336.

40. Meade, T.W., G.J. Miller, and R.D. Rosenberg. 1992. Characteristics associated with the risk of arterial thrombosis and the prethrombotic state. In Thrombosis in Cardiovascular Disorders. V. Fuster and M. Verstraete, editors. W.B. Saunders Company, Philadelphia. 79-97.

41. Zoeller, B., A. Hillarp, E. Berntorp, and B. Dahlback. 1997. Activated protein $\mathrm{C}$ resistance due to a common factor $\mathrm{V}$ gene mutation is a major risk factor for venous thrombosis. Ann. Rev. Med. 48:45-58.

42. Miletich, J.P., S.M. Prescott, R. White, P.W. Majerus, and E.G. Bovill. 1993. Inherited predisposition to thrombosis. Cell. 72:477-480.

43. Lane, D.A., P.M. Mannucci, K.A. Bauer, R.M. Bertina, N.P. Bochkov, V. Boulyjenkov, B. Dahlback, E.K. Ginter, J.P. Miletich, F.R. Rosendaal, et al. 1996. Inherited thrombophilia: Part 1. Thromb. Haemost. 76:651-662. 